\author{
Military Technical College \\ Kobry El-Kobbah, \\ Cairo, Egypt.
}

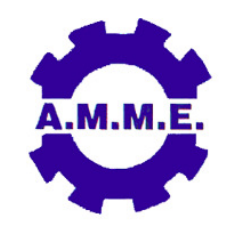

\title{
FE SIMULATION STUDY OF ULTRA-PRECISION TURNING OF STAINLESS STEEL 316L
}

\author{
A. Abdelaziz ${ }^{1}$ A. Elkaseer ${ }^{2}$, M. Saber ${ }^{3}$ and A. Nassef ${ }^{4}$
}

\begin{abstract}
This paper presents a simulation-based study of ultra-precision turning of hard-to-cut stainless steel 316L. In particular, Finite Element modeling was implemented to simulate the chipping process of stainless steel $316 \mathrm{~L}$ under restricted process parameters. The aim of this investigation was to understand the underlying cutting phenomena under precise conditions. The simulation outcomes were validated by experimental results that were obtained by the authors in preceding work. A good agreement between both results was found which confirmed the initial hypothesis that FEM is a reliable means to simulate the cutting process accurately and thus to identify the optimum cutting conditions for the best possible performance of the process. The simulation results revealed that the minimum chip thickness of stainless steel $316 \mathrm{~L}$ was determined to be $69 \%-75 \%$ of the cutting edge radius of the tool.
\end{abstract}

\section{KEY WORDS}

FEM, simulation study, ultra-precision turning, chipping mechanisms, shear angle

1 Northern Workshop, Port Said Shipyard, Suez Canal Authority. Email: aliabdelaziz2006@yahoo.com

2 Lecturer of Production Eng., Faculty of Eng., Port Said University. Email: elkaseeram@gmail.com

3 Lecturer of Production Eng., Faculty of Eng., Port Said University (on leave) \& Assistant Prof.

Department of mechanical Eng., College of Eng., King Faisal University, Kingdom of Saudi Arabia.

Email: mssaber77@yahoo.com.

4 Prof. of Production Eng., Faculty of Eng., Port Said University. Email: nassef12@hotmail.com 


\section{INTRODUCTION}

The emergence and subsequent rapid development of miniaturisation technologies is considered the milestone of recent era [1]. Amongest these technologies, ultraprecision turning is a fruitful method for producing cylindrical parts with micro features and thus it is widely used in micro-manufacturing applications [1]. However, the full capabilities of ultra-precision turning have not been fully implemented. This is mainly owing to the constraints of the size-scale at which the process takes place. Especially, in ultra-precision turning, the applied feed and the cutting edge radius of the tool are comparable in scale. Consequently, the physical principles that govern the underlying mechanisms of this technology can be substantially different from those at the conventienal macro-scale [2]. This can reuslt in undesirable changes of the chip formation process, tool wear mechanisms and surface genration process [2]. Many researchers have dedicated their work to investigate the conventional turning experimentally and theoretically. In contrast, with micro-turning, most of the research reported have been experimental with relatively few analytical attempts made to model the the ultra-precision tuning process. With the help of FEA the optimum cutting parameters can be identified which enable high quality of the machined surface and allows minimizing tool wear and in turn increasing the productivity of the process [3]. The motivation for this research was to to deal with the lack of full scientific understanding of the ultra-precsion turning for mature practice of the process. In this context, the aim of this paper is to conduct a Finite Element-based study to understand better the process of chip formation, assocaited chip shear angle and surface generation under a range of cutting conditions.

In particular, a series of simulation trials have been carried out and the results of such simulation have been validated with experimental results that had been published in previous work by the authors [4]. This paper is organized as follows. Firstly a review of most related work is presented. Secondly, the systematic procedure followed to carry out the simulation study is given. Thirdly the achievable results of the simulation tests are described followed by a discussion of the agreement and discrepancy between these results and the experimental ones. Finally the paper summaries with some conclusions based on the results and discussions.

\section{RELATED WORK}

A noticeable number of researches conducted simulation studies via FEA for different machining processes to validate the experimental work aiming at figuring out the optimum parameters during the operations.

F. Shao et. al., [5] studied the cutting temperature and tool wear during the turning process of Ti-6Al-4V alloy with WC-Co cutting tool. A FEA method using thermodynamical constitutive equation was used to undertake a comparison between the simulation predictions and the experimental results of cutting temperature and tool wear depth. The results indicated a good matching accuracy between the practical and FEA model using thermo-dynamical constitutive equation if the correct parameters for the workpiece and cutting tool were chosen. 
F. Akbar et. al., [6] investigated the heat generated in machining process with an experimental test, a validation for the experimental work with a FE model done for better understanding of heat partition between the cutting tool and the deformed chip. The cutting temperature was measured using infrared thermal imaging camera. The results showed that heat partition can significantly modify the tool-chip contact area and hence it affected the capability of FE model to adequately represent the process. Also, an accurate determination of heat partition between the tool and the chip was found an important input for proper simulation of the machining process.

L. Zhou et. al., [7] carried out a two-dimensional orthogonal cutting experiments for the machining of SiCp/Al composites with a polycrystalline diamond tool. In addition, the study examined the cutting force and von Misses equivalent stress at different cutting conditions with a thermal-displacement coupled FE model. Based on the experimental and simulation results it was demonstrated that during machining of $\mathrm{SiCp} / \mathrm{Al}$ composites the cutting speed should be as high as possible but the opposite was valid for the cutting depth. Also the removal mechanism of SiCp depended on the location of the cutting tool with respect to the particle.

B. Li, [8] used the Finite element method to predict the tool wear evolution and tool life in orthogonal cutting with FEM simulations and the cutting process variables which were considered difficult to obtain with experimental methods.

S. Yang et. al., [9] examined the Mechanical behavior of hydro-generated Ti-6Al-4V alloy at elevated temperatures and high strain rates with split Hopkinson pressure bar using FEM and $\mathrm{J}-\mathrm{C}$ constitutive equation. A numerical model was developed to simulate the cutting process. The results presented a significant effect on the cutting forces and temperature, when increased the hydrogen contents, the cutting forces and temperature increased initially and then decreased gradually. From the simulation, the result revealed that the titanium alloys with $0.3 \%$ hydrogen had better machinability at high cutting speed.

M. Stalin John et. al., [10] investigated the effect of different cutting speeds, depth of cut, and feeds on the surface roughness when cutting AISI 1020 steel using two different cutting tools; the first one was a single-point cutting tool (HSS) and the second was insert tool (CNMA WC). This investigation carried out experimentally and using FEM. From the results the minimum and maximum deviation between the experimental work and the FEM was 3.74 and $22.8 \%$ for single point tool and 1.15 and $11.8 \%$ for the insert. Also a better surface finish on AISI 1020 using insert tool was achieved at feed of $0.05 \mathrm{~mm} / \mathrm{rev}$, cutting speed of $327.28 \mathrm{~mm} / \mathrm{min}$, and depth of cut equaled 0.5 $\mathrm{mm}$. However, the surface finish achieved by the insert tool was better than the surface finish from H.S.S tool.

B. Haddag et. al., [11] examined the effect of heat transfer on the cutting tool with a new modeling strategy based on two steps of calculations. The first step was a 3D thermo-mechanical modeling of the chip formation process, which helped in estimating cutting forces and its flow direction. The second step was a 3D thermal modeling of the heat diffusion into the cutting tool by using an adequate thermal loading. This loading was estimated using some quantities obtained from the first step such as contact pressure, sliding velocity distributions and contact area. The comparison between the modeling process and the experimental data showed a good agreement. 
M. Ali et. al., [12] studied the machining process of Ti-6Al-4V with experimental and FEM. The simulation results of FEM proved an agreement between the FE results and the experimental data during the machining process. It was found that there is a significant difference in terms of simulation technique using FEM and modifications of the $\mathrm{J}-\mathrm{C}$ model. However, a little difference was observed between them in terms of procedures. Furthermore, the true criterion was defined to find the lowest error between the experimental cutting findings and estimation values using FEM.

V. Bushlya et. al., [13] proposed a model for the formation of machined subsurface layer in turning with nose-radiused tools and also presented an experimental validation for this simulation study. The model showed that a multiple deformation of the workpiece material occurs in the vicinity of the tip of the nose-radiused tool. This observation of the multiple deformations of the machined surface occurred when machining with small feeds and tools with large nose radius, which indicated change of the mechanics of surface formation. The model also showed that the significant part of the cutting tool may subject to sever wear due to the extra work-hardened material.

J. Aurich et. al., [14] analyzed the accuracy of machining in dry turning operation via experiments and finite element simulations. The results revealed a major effect of the cutting conditions used in machining operation on the remaining quantities of heat on the workpiece, cutting tool, tool holder and thus on the accuracy of machining process. Also the best machining accuracy achieved using the greatest value of cutting speed and feed at the least depth of cut. The authors concluded that the temperatures of both the tool and the tool holder need to be taken into consideration in order to enhance the accuracy of machining.

\section{MODELING AND SIMULATION}

For simulation process, a CAE ABAQUS explicit software was used. A proposed program was designed to conduct the simulation of the chipping process during ultraprecision turning operation. The implement the simulation process, sequential steps have to be undertaken to achieve accurate results. These steps were performed inside the software depending on the cutting process parameters. These steps are as follows.

\section{Design of Workpiece and Cutting Tool}

The first step is to create the part modeling of the cutting tool and the workpiece. There are two different ways for modeling, one of them is two dimension modeling and the other one is three dimensional modeling. In this study, three dimensional modeling approach was used, owing to its superior capabilities of giving better visualization of the chip formation process.

\section{Workpiece and Cutting Tool Material Mechanical and Physical Properties}

Inside the software, the mechanical properties of the workpiece and the cutting tool material were entered. These properties were fed into the software for Stainless Steel 316L Table 1 to Table 3, which covers the mechanical and physical properties of the 
workpiece cutting tool materials. It is important to state that, the precision of the obtainable results is a function of the accuracy of these data.

\section{Numerical Model for the Cutting Process}

Johnson cook damage model was utilized to simulate the cutting process. Some parameters are required to identify the cutting tool material behavior during the simulation process. These parameters grouped together in Table 4 . The same parameters also for the workpiece are listed in Table 5.

\section{Mesh Generation and Study}

A 3D model for the cutting tool and the workpiece was developed. The mesh type used for modeling is linear hexahedron C3D8R for the workpiece and C3D4 for the cutting tool. The mesh size was chosen to pay more concentration to the cutting tool tip which is the important part during the cutting process. So, the size of the element was decreased on the tip area of the tool and increased gradually far from the insert tip, Fig.1a. The same idea was used in modeling the workpiece material to focus on the chip separation region as shown in Fig.1b.

\section{Assembly}

The cutting tool and the workpiece were assembled together to achieve the real experimental angles and position, see Fig. 2 illustrates a side view for the simulation of the cutting process.

\section{Boundary Conditions}

The boundary condition data needed by ABAQUS to solve the problem are discussed below; initially the workpiece was fixed at its bottom surface and the cutting tool was fixed in $\mathrm{Y}$ - and Z-directions but allowed to move in X-direction with cutting speed of $120 \mathrm{~m} / \mathrm{min}$, similar to this applied in the experimental trials. Fig.3 and Table.6 summarize the boundary conditions applied to both of the tool and the work piece.

\section{Run and Simulation}

After finalizing all the steps required for the modeling process, the final step is to carry out the calculations by initiating the running of the simulation process. At this step the software run the calculation based on the data entered for the workpiece material and the cutting tool material. 


\section{RESULTS AND DISCUSSIONS}

This section presents the obtained results and related discussions that involve the results of the chipping formation process and the shear angle calculation via the FEA.

\section{Chip Formation}

Figures from Fig. 4 to Fig. 10 illustrate the chip formation from experimental work alongside the chip obtained from the simulation. It is not so difficult to see that there is a convergence between the results of both experiment and simulation. From the figures it is clearly appeared that the cutting process and chip formation from feed rate of $0.01 \mathrm{~mm} / \mathrm{rev}$ to feed rate $0.03 \mathrm{~mm} / \mathrm{rev}$ are not similar to the results from feed rate $0.03 \mathrm{~mm} / \mathrm{rev}$ to feed rate $0.07 \mathrm{~mm} / \mathrm{rev}$. In particular, the chip formation at the very low feed rates is not considered pure cutting. However, it is a mixed cutting and ploughing which is a result of the comparable size scale between the tool edge radius and the feed rate. This relationship governs the chip formation process. Especially, when the underformed chip thickness is blow a certain value, the so-called minimum chip thickness, no cutting takes place and only ploughing and plastic deformation of the material is the dominant mechanism. From the simulation, it was found that when applying feed below the tool edge radius, no chipping is deformed and the material is compressed underneath the cutting tool along the cutting tool path. This occurs and the deformed material aggregated in from of the cutting edge radius until the thickness of the material exceeds the so-called minimum chip thickness. Then the separation of the chip occurs and the process repeated again and again. At the higher values of feed rate which is starting from the value equals the tool edge radius and above, the chip formation process started to be normal and the chip becomes more longer and the formation process become continuous. It is worth emphasizing that the transition of both underlying regimes is very important in this cutting scale. In particular, at such critical point the optimal cutting conditions are identified, where the lowest force and high surface quality can be achieved.

In Fig. 4 the feed rate is $0.01 \mathrm{~mm} / \mathrm{rev}$. The cutting process produced a distorted chip which is a result of mixed cutting and metal forming process. At this value of feed rate the stresses are very high and the surface roughness is not good due to the tearing happened in the machined surface. Also from the simulation the generated heat is very high due to high friction.

Fig. 5 shows the simulation at feed rate of $0.02 \mathrm{~mm} / \mathrm{rev}$. With the increase of the feed rate the shape of the resultant chip is changed but still distorted. At this value of feed rate the stresses are still very high and the surface roughness also is not good due to the same reasons happened at feed rate $0.01 \mathrm{~mm} / \mathrm{rev}$ due to the effect of minimum chip thickness .

In Fig. 6 the feed rate is $0.03 \mathrm{~mm} / \mathrm{rev}$. The increase of the feed rate the shape of the chip started to be much longer and the chip formation process stared to be stable. At this value of feed rate the stresses started to decrease where the effect of minimum chip thickness reduced associated with proper cutting and much better surface generation. 
Fig. 7 and Fig. 8 illustrate the simulation at feed rate of $0.04 \mathrm{~mm} / \mathrm{rev}$ and $0.05 \mathrm{~mm} / \mathrm{rev}$, respectively. With the increase of the feed rate until its value reached the tool edge radius and above, the shape of the chip became more consistence and the stresses values reduced and better surface roughness started achieved.

In Fig. 9 and Fig. 10 the feed rate is $0.06 \mathrm{~mm} / \mathrm{rev}$ and $0.07 \mathrm{~mm} / \mathrm{rev}$. The simulation process produced conventional chip formation models and the chip is longer than the previous feed rates. At this value of feed rate there is no significant change in the stresses values and also the change in surface roughness is no too much.

\section{Shear Angle}

It has been observed that during machining, particularly ductile materials, the chip sharply changes its direction of flow (relative to the tool) from the direction of the cutting velocity, $\mathrm{VC}$ to that along the tool rake surface after thickening by shear deformation or slip or lamellar sliding along a plane. This plane is called shear plane and is schematically shown in Fig.11.

$$
\tan \beta_{0}=\frac{\mathbf{r} \cos \gamma}{1-\mathbf{r} \sin \gamma} \quad \text { (Eq. 1.1) }
$$

where $\beta_{0}=$ Shear angle $\& r=$ chip ratio $=$ feed $/$ chip thickness $\& \gamma=$ rake angle $=-5^{0}$ The shear angle was measured in simulation for all feed rates and also the chip thickness Fig.12. From the (equation.1.1) the actual shear angle was calculated and compared with the measured one from the simulation and the results illustrated in Table.7 and it is clear from the results that there is a good agreement between the actual and simulation shear angle value and this considered as a good indicator for the Capabilities of the FEA method.

\section{CONCLUSION}

This paper has reported on FE modeling and simulation process of the chip formation during turning operation of stainless steel $316 \mathrm{~L}$. In order to judge the feasibility of the FE approach, the results were compared with those obtained by an experimental study that was undertaken by the authors in previous work. In particular, the morphology of the formed chips in additions to the value of the shear angle were utilized as comparison criteria between FE simulations and experimental results.

From the simulation process, a strong relationship between the cutting tool edge radius and applied feed rate and the dominant cutting mechanism was revealed. This relationship controlled the chip formation process. In particular, the transition between mixed cutting/ploughing regimes into pure cutting mechanism when the feed rate exceeded the minimum chip thickness values was observed, that allowed to identify the minimum chip thickness of stainless steel $316 \mathrm{~L}$ at $69 \%-75 \%$ of the cutting tool edge radius value. When the applied feed equaled or just beyond the value of the minimum chip thickness, conventional chip formed and the cutting mechanism altered from ploughing to pure cutting. This is considered the optimum cutting condition, were the lowest stresses were detected and the minimum surface roughness was achieved. 
It can be concluded that the FEA is a powerful engineering tool and the FE results help in predicting and calculating different parameters prior the actual metal cutting process. In this context, the authors intend to carry out further FEA to gain deeper understanding of the metal machining operations, especially the ultra-precision turning process.

\section{REFERENCES}

[1] V. Senthilkumar and S. Muruganandam, "State of the art of micro turning process", International Journal of Emerging Technology and Advanced Engineering, ISSN 2250-2459, Volume 2, Issue 2, (2012)

[2] T. Jagadesh. and G. L. Samuel, "Finite Element Modeling for Prediction of Cutting Forces during Micro Turning of Titanium Alloy", 5th International \& 26th All India Manufacturing Technology, Design and Research Conference (AIMTDR) December 12th-14th, IIT Guwahati, Assam, India, (2014).

[3] N. Senthil Kumar and T. Tamizharasan, "Finite element analysis and optimization of uncoated carbide cutting inserts of different tool geometries in machining aisi 1045 steel", Journal of Mechanical Sciences, Vol. 1 No. 1, pp 37-47, ISSN : $2231-4768$

[4] A. Abdelaziz, A. Elkaseer, A. Nassef, Tool Wear and Surface Roughness in Hard Turning of Stainless Steel 316L Using Tungsten Carbide Tool, 8th international Engineering Conference, Al-Mansoura - Sharm El-Sheikh, 17 22 November, (2015).

[5] F. Shao, Z. Liu, Y. Wan and Z. Shi, "Finite element simulation of machining of Ti- 6Al-4V alloy with thermodynamical constitutive equation", Int J Adv Manuf Technol 49:431-439 DOI 10.1007/s00170-009-2423-y, (2010).

[6] F. Akbar, P. T. Mativenga and M. A. Sheikh, " An experimental and coupled thermo-mechanical finite element study of heat partition effects in machining", Int J Adv Manuf Technol 46:491-507-DOI 10.1007/s00170-009-2117-5, (2010).

[7] L. Zhou, S. T. Huang, D. Wang and X. L. Yu, "Finite element and experimental studies of the cutting process of SiCp/Al composites with PCD tools", Int J Adv Manuf Technol 52, 619-626-DOI 10.1007/S00170-010-2776-2, (2011).

[8] B. Li, "A review of tool wear estimation using theoretical analysis and numerical simulation technologies", Int. Journal of Refractory Metals and Hard Materials 35-143-151, Elsevier Ltd. All rights reserved, DOI:10.1016/j.jijmhm.2012.05.006, (2012).

[9] S. B. Yang, J. Xu, Y. Fu and W. Wei, "Finite element modeling of machining of hydrogenated Ti-6Al-4V alloy", Int J Adv Manuf Techno-59:253-261-DOI 10.1007/s00170-011-3479-z, (2012).

[10] M. R. Stalin John, K. Shrivastava , N. Banerjee , P. D. Madhukar and B. K. Vinayagam, "Finite Element Method-Based Machining Simulation for Analyzing Surface Roughness During Turning Operation with HSS and Carbide Insert Tool", Arab J Sci Eng 38:1615-1623 DOI 10.1007/s13369-0130541-1, (2013).

[11] B. Haddag , T. Kagnaya, M. Nouari and T. Cutard, "A new heat transfer analysis in machining based on two steps of 3D finite element modeling and experimental validation", Heat Mass Transfer 49:129-145, DOI 10.1007/s00231-012-1069-8, (2013). 
[12] M. Ali, M. N. M. Ansari, B. A. Khidhir, B. Mohamed and A. A. Oshkour, "Simulation machining of titanium alloy (Ti-6Al-4V) based on the finite element modeling", J Braz. Soc. Mech. Sci. Eng. 36:315-324 DOI 10.1007/s40430013-0084-0, (2014).

[13] V. Bushlya, J. Zhou and J. Stahl, "Modeling and experimentation on multistage work-hardening mechanism in machining with nose-radiused tools and its influence on machined subsurface quality and tool wear", Int J Adv Manuf Technol 73:545-555 DOI 10.1007/s00170-014-5837-0, (2014).

[14] J. C. Aurich, M. Zimmermann, S. Schindler and P. Steinmann, "Analysis of the machining accuracy when dry turning via experiments and finite element simulations", prod. Eng. Res. Devel-8:41-50 DOI 10.1007/s11740-013-05089, (2014).

[15] N. Sawarkar and G. Boob, "Finite Element based Simulation of Orthogonal Cutting Process to Determine Residual Stress Induced", International Journal of Computer Applications (0975 - 8887), (2014).

[16] Physical properties of stainless steel 316L, URL: http://www.aksteel.com/pdf/markets products/stainless/austenitic/ 316316 l data sheet.pdf, last access 6/12/2015.

[17] Mechanical properties of $316 \mathrm{~L}$ grade stainless steel, URL:http://www.efunda.com/materials/alloys/stainless steels/show stainless .cfm?ID=AISI Type 316L\&prop=all\&Page Title=AISI\%20Type\%20316L, last access 6/12/2015. 
Table 1. Mechanical properties of 316L grade stainless steel [17].

\begin{tabular}{|c|c|c|c|c|c|}
\hline \multirow[b]{2}{*}{ Grade } & \multirow{2}{*}{$\begin{array}{l}\text { Tensile } \\
\text { str } \\
\text { (MPa)min }\end{array}$} & \multirow{2}{*}{$\begin{array}{c}\text { Yield str } 0.2 \% \\
\text { proof(MPa) } \\
\text { min }\end{array}$} & \multirow{2}{*}{$\begin{array}{c}\text { Elong } \\
(\% \text { in50mm)min }\end{array}$} & \multicolumn{2}{|c|}{ hardness } \\
\hline & & & & $\begin{array}{c}\text { Rockwell } \\
\text { max }\end{array}$ & $\begin{array}{c}\text { Brinell } \\
\max \end{array}$ \\
\hline $316 \mathrm{~L}$ & 515 & 205 & 40 & 95 & 217 \\
\hline
\end{tabular}

Table 2. Physical properties of 316L grade stainless steel [16].

\begin{tabular}{|c|c|c|c|}
\hline Grade & $\begin{array}{c}\text { Density } \\
\mathrm{kg} / \mathrm{m}^{3}\end{array}$ & Elastic modulus (GPa) & Specific heat 0-100 $\mathrm{C}$ \\
\hline $316 \mathrm{~L}$ & 8000 & 193 & 500 \\
\hline
\end{tabular}

Table 3. Mechanical and physical properties of cutting tool material, WC-CO [5].

\begin{tabular}{|l|l|}
\hline Density & $14.5^{\star} 103 \mathrm{~kg} / \mathrm{m}^{3}$ \\
\hline Ultimate tensile strength(MPa) & 3,000 \\
\hline Modulus of elasticity(GPa) & 650 \\
\hline Thermal conductivity $(\mathrm{W} /(\mathrm{mK}))$ & 58.9888 \\
\hline Poisson's ratio & 0.25 \\
\hline Heat capacity $(\mathrm{j} / \mathrm{kg} \mathrm{K})$ & 15.0018 \\
\hline
\end{tabular}

Table 4. Johnson cook parameters for WC-CO [5].

\begin{tabular}{|c|c|c|c|c|c|}
\hline Constant & A & B & C & $n$ & $m$ \\
\hline WC-CO & 0.003 & 8.0471 & 0.00 & 0.0003 & 0.179 \\
\hline
\end{tabular}

Table 5. Johnson cook parameters for ST.ST 316L [15].

\begin{tabular}{|c|c|c|c|c|}
\hline $\mathbf{A}(\mathbf{M P a})$ & $\mathbf{B}(\mathbf{M P a})$ & $\mathbf{N}$ & $\mathbf{M}$ & $\mathbf{C}$ \\
\hline 490 & 600 & 0.21 & 0.6 & 0.015 \\
\hline $\mathbf{D 1}$ & $\mathbf{D 2}$ & $\mathbf{D 3}$ & $\mathbf{D 4}$ & $\mathbf{D 5}$ \\
\hline 0.05 & 3.44 & 2.12 & 0.002 & 0.61 \\
\hline
\end{tabular}


Table.6. Detailed boundary conditions for workpiece and cutting tool model.

\begin{tabular}{|l|c|c|}
\hline \multicolumn{1}{|c|}{ Boundary condition } & Workpiece & Cutting tool \\
\hline Displacement in $\mathrm{x}$ axis $=\mathrm{Ux}_{\mathrm{x}}$ & 0 & $-150 \mathrm{~mm}$ \\
\hline Displacement in y axis $=U_{Y}$ & 0 & 0 \\
\hline Displacement in $\mathrm{z}$ axis $=\mathrm{Uz}_{\mathrm{z}}$ & 0 & 0 \\
\hline Velocity & 0 & $120 \mathrm{~m} / \mathrm{min}$ in $\mathrm{x}$ axis direction \\
\hline
\end{tabular}

Table.7. Comparison between the actual and simulation shear angle.

\begin{tabular}{|c|c|c|c|c|}
\hline $\begin{array}{c}\text { Feed } \\
\text { rate } \\
(\mathrm{mm} / \mathrm{rev})\end{array}$ & $\begin{array}{c}\text { Chip } \\
\text { thickness(mm) }\end{array}$ & $\begin{array}{c}\text { Actual shear } \\
\text { angle(degree) }\end{array}$ & $\begin{array}{c}\text { Simulation } \\
\text { shear } \\
\text { angle(degree) }\end{array}$ & $\begin{array}{c}\text { Error } \\
\text { percentage } \\
\%\end{array}$ \\
\hline 0.04 & 0.092 & 22.4 & 26.05 & -16 \\
\hline 0.05 & 0.085 & 29.13 & 38.26 & -31 \\
\hline 0.06 & 0.11 & 27.41 & 35.03 & -28 \\
\hline 0.07 & 0.13 & 27.12 & 33.2 & -22 \\
\hline
\end{tabular}
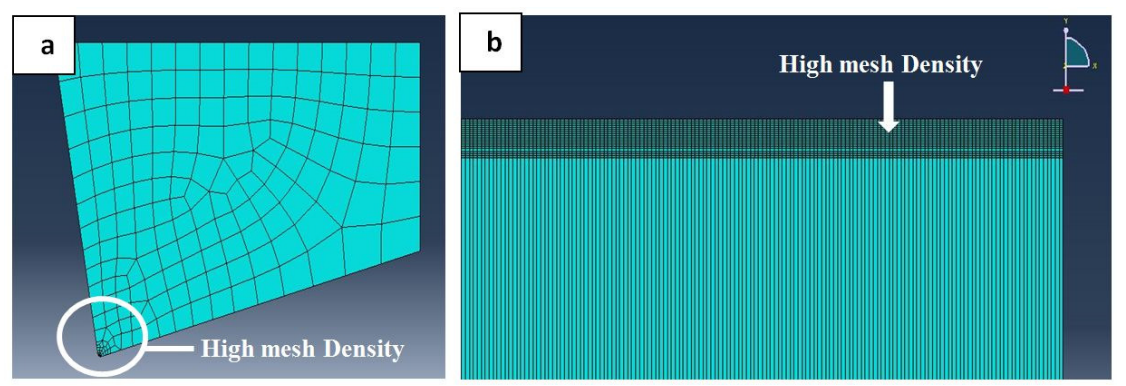

Fig.1. Meshing of the (a) Cutting tool and (b) workpiece.

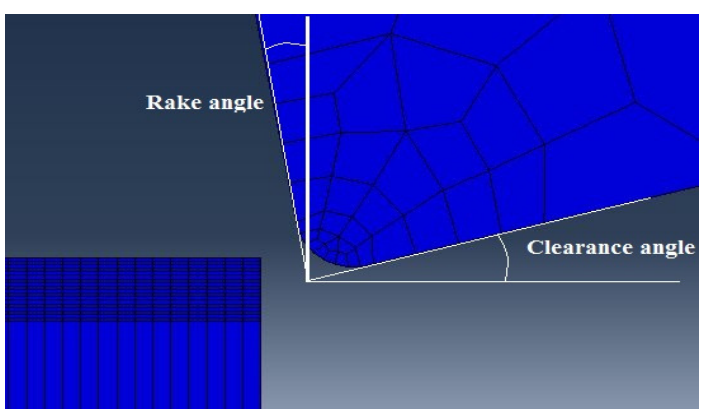

Fig.2. Side view of the modeling assembly. 


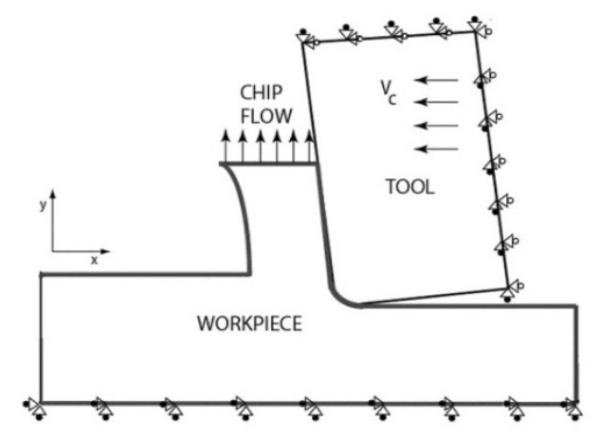

Fig.3. Boundary conditions for workpiece and cutting tool model.
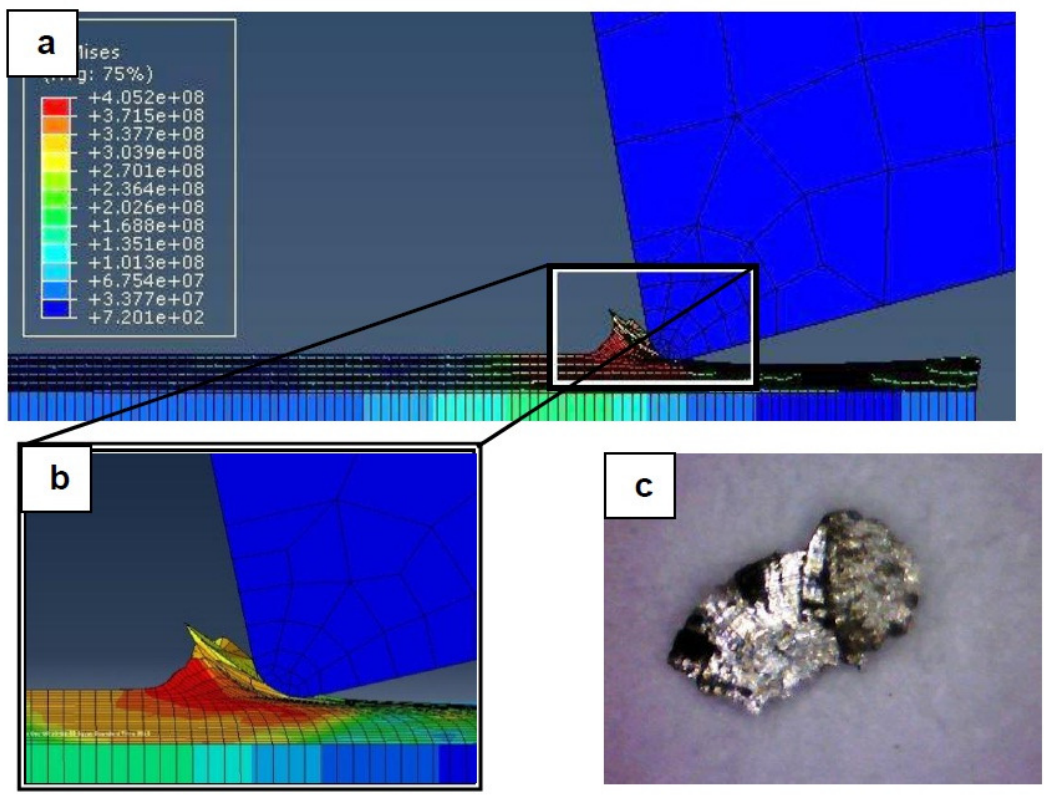

Fig.4. Chip formation at feed rate $0.01 \mathrm{~mm} / \mathrm{rev}$

(a) Chip formation (b) Simulation detailed view (c) Experimental result.

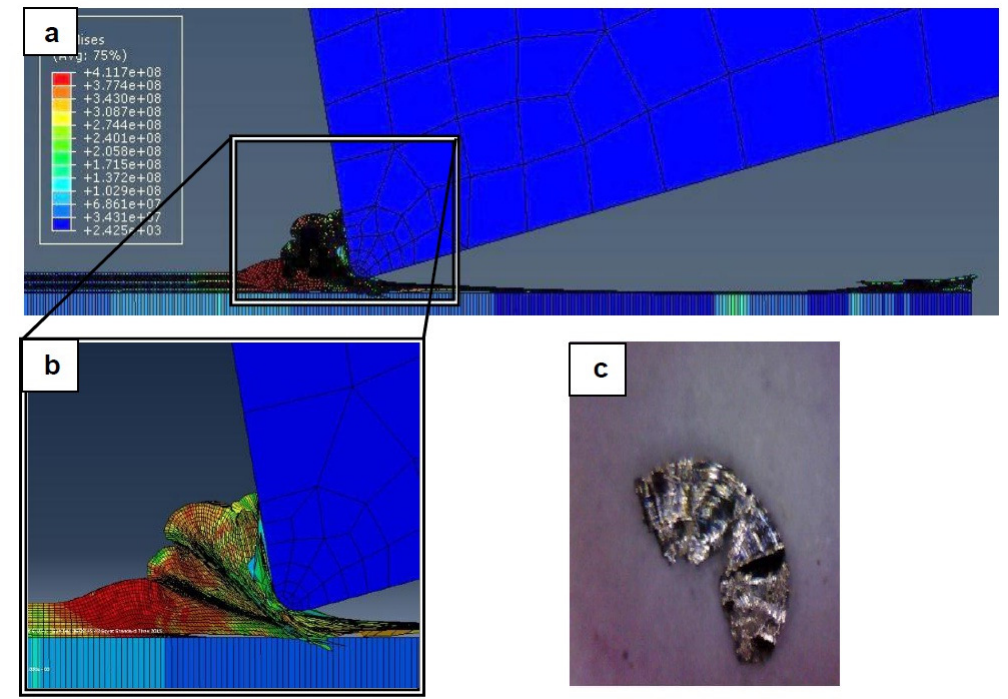

Fig.5. Chip formation at feed rate $0.02 \mathrm{~mm} / \mathrm{rev}$ (a) Chip formation (b) Simulation detailed view (c) Experimental result 

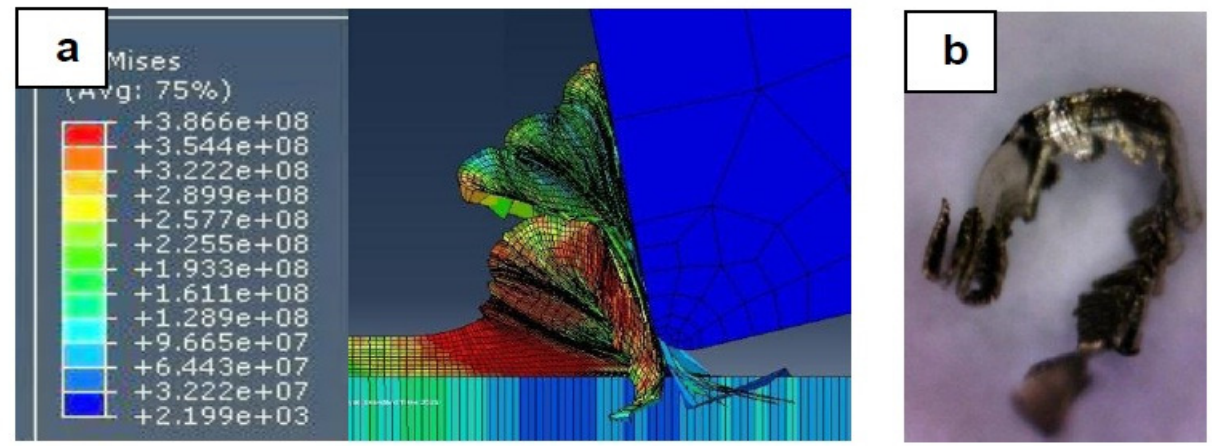

Fig.6. Chip formation at feed rate $0.03 \mathrm{~mm} / \mathrm{rev}$ (a) Simulation detailed view (b) Experimental result
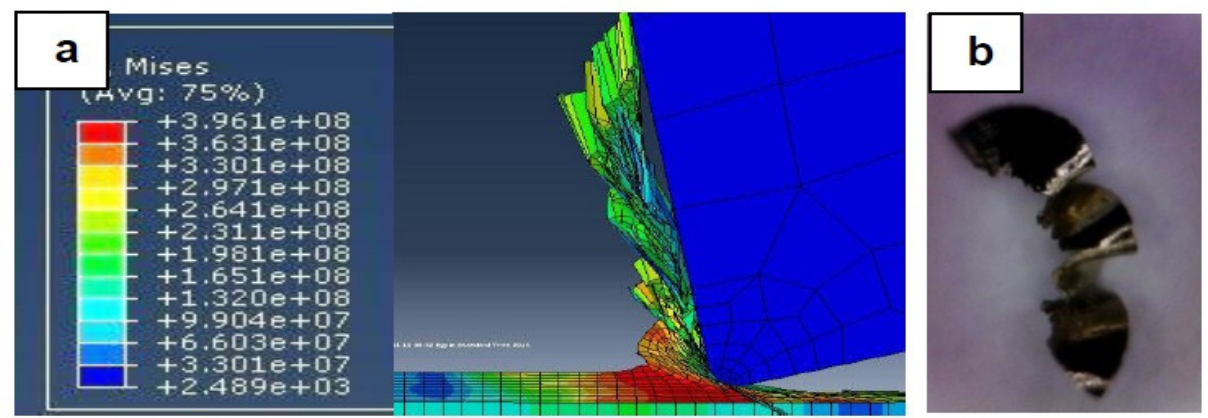

Fig.7. Chip formation at feed rate $0.04 \mathrm{~mm} / \mathrm{rev}$ (a) Simulation detailed view (b) Experimental result
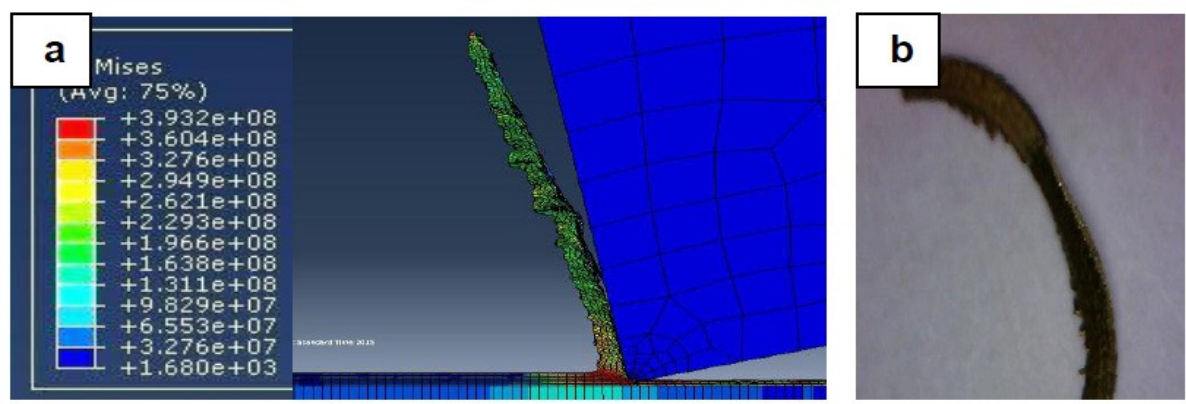

Fig.8. Chip formation at feed rate $0.05 \mathrm{~mm} / \mathrm{rev}$ (a) Simulation detailed view (b) Experimental result
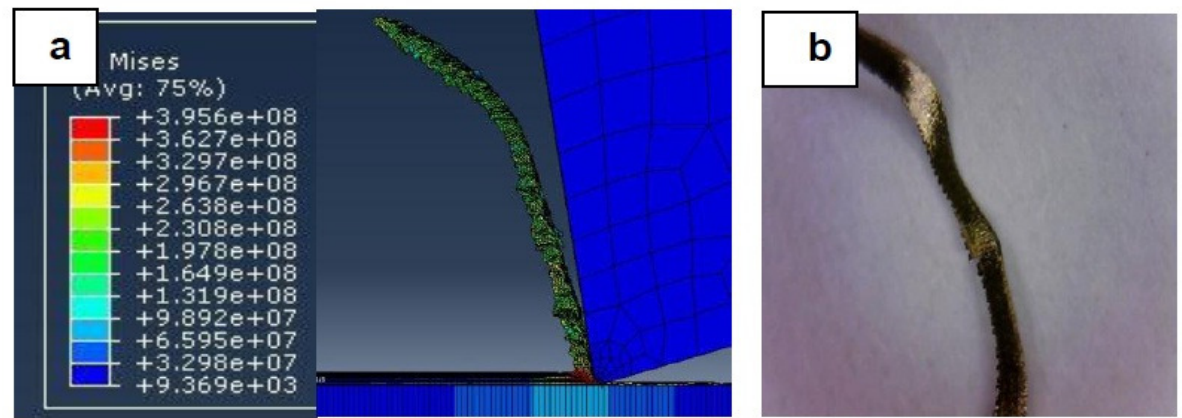

Fig.9. Chip formation at feed rate $0.06 \mathrm{~mm} / \mathrm{rev}$ (a) Simulation detailed (b) view Experimental result 

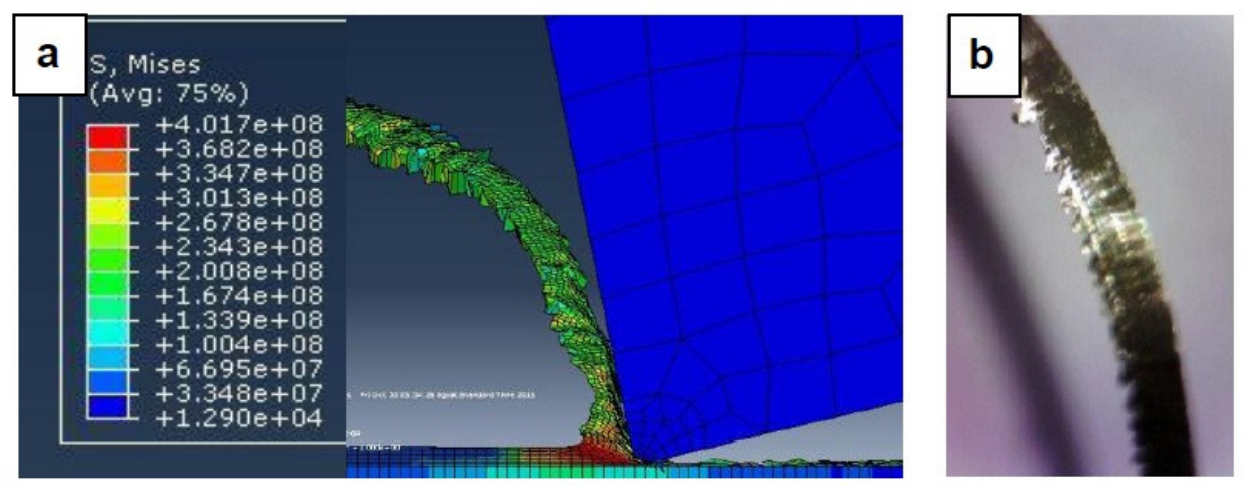

Fig.10. Chip formation at feed rate $0.07 \mathrm{~mm} / \mathrm{rev}$ (a) Simulation detailed view (b) Experimental result

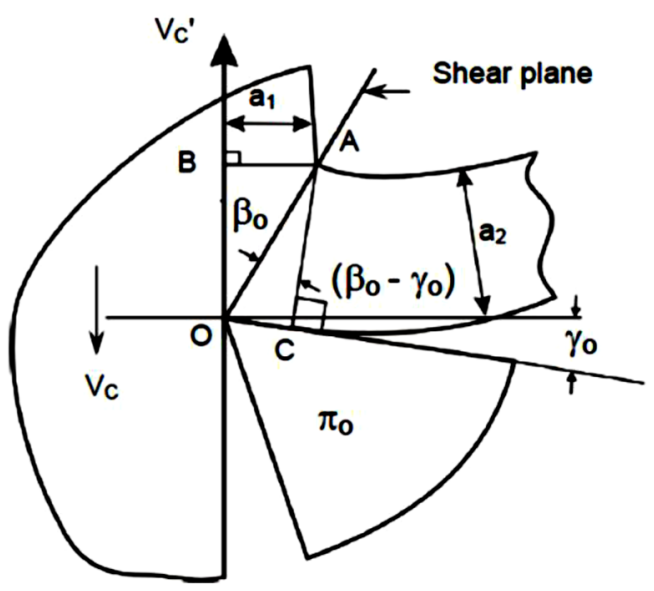

Fig.11. Shear plane and shear angle in chip formation
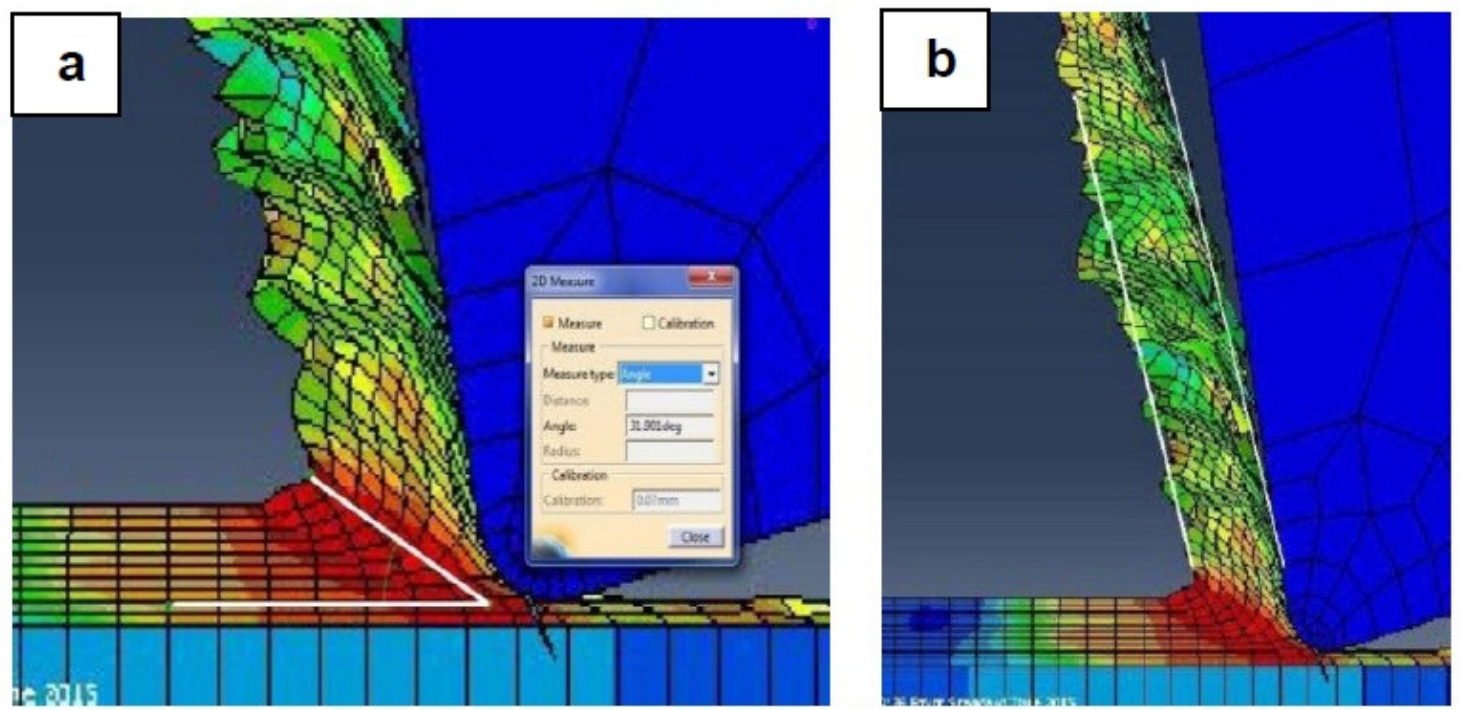

Fig.12. Shear angle and chip thickness measuring in simulation (a) Shear angle measurement (b) Chip thickness measurement 